\title{
Impact of Flex-Work on Employee Performance: Study of Executive-Level Employees in IT Industry of Sri Lanka
}

\author{
S. W. A. W. M. D. Nayanathara ${ }^{1}$ and R. A. I. C. Karunarathne ${ }^{2}$ \\ ${ }^{1,2}$ Department of Human resource Management, Faculty of Commerce and \\ Management Studies, University of Kelaniya, Sri Lanka \\ ${ }^{1}$ duneeshi1996N@gmail.com, ${ }^{2}$ ishankac@kln.ac.lk
}

\begin{abstract}
Employee performance plays an important role in every organization. In the modern business world, it is important to examine the effect of flex-work on employee performance as it is a widely discussed topic during the COVID-19 pandemic situation. Although, scholars have already examined the effect of flex-work practices and their outcomes, the results are inconsistent. Thus, the current study aimed to examine the lacuna in literature, which is impact of flex-work on employee performance. To attain this purpose, researchers collected data from 169 executive-level employees in three IT firms in Western Province, Sri Lanka. Data were analyzed using descriptive statistics, correlation, and regression with the aid of SPSS. The findings of the study revealed that there is a significant impact of flex-work on employee performance, where employee performance will increase with the improvements in flex-work. Theoretical and practical implications are discussed.
\end{abstract}

Keywords: Employee Performance, Executive-Level Employees, Flex-work, IT Industry

\section{Introduction}

The prevailing COVID-19 global health crisis is unprecedented. It is considered as one of the turning points in history. It is shuffling social and economic norms while triggering a new human era. The magnitude and speed of collapse in numerous activities that have followed are unlike anything experienced in our lifetime. Furthermore, with social, economic, and health systems on the verge of collapsing, it is impossible to imagine what the new business world will look like; however, its shape will depend on the decisions taken by the organization today.

Similarly, organizational continuity and sustainability depend upon the organizational ability to move swiftly and effectively in developing policies and procedures affecting the organization and meet medium and long-term needs. Flexibility has developed as a key policy adopted to build more substantial, more viable firms with committed, more productive employees (Rawashdeh, Almasarweh \& Jaber, 2016). According to Weerasinghe and Jayawardana (2019), flex-work is a popular and respected practice throughout the world today, and as a result of flex-work, employees have to experience timeless, borderless, and endless jobs.

According to Kipkoech (2018), employee performance is defined as a work-related task that is expected on 
employees and how well the task was done. Furthermore, Muda, Rafiki, and Harahap (2014) stated that within the framework of the professionals, good employee performance mirrors the ability to contribute through their works leading to the behavioral achievement that is in accordance with the goals of the company. According to Georgiana and Constantin (2017), there have been situations in which such flexibility offered to the employees of a company failed to reach the expected targets, and quite on the contrary, it bought inefficiency. Moreover, the COVID-19 pandemic has placed flexible work arrangements, especially telework, in the spotlight. Due to this reason, only essential businesses were allowed to keep their physical locations open, and unprepared employers were forced to implement flexible work options. In addition to that, to the best of the researchers' knowledge, only a few researchers have made a comprehensive attempt to explore the impact of flex-work on employee performance after this COVID-19 pandemic.

Additionally, there are some employee performance issues in many organizations because of this COVID19 pandemic. Therefore, examine the impact of flex-work on employee performance will be very important these days. According to Vaatstra (2012), the effects of flex-work practices are studied thoroughly but are further debated. There is no clear evidence of the relation between flexwork and performance (Menezes \& Kelliher, 2011, for more review, see, Taskin, Donis \& Caesens, 2019). Therefore, previous theoretical explanations and empirical findings related to the impact have been inconsistent. That is why the present study intends to fulfill the gap in the literature as well. Hence, this study addresses the lacuna in empirical studies examining the impact of flexwork on employee performance and since the previous theoretical explanations and empirical findings related to the impact have been inconsistent, much remains to be learned about this impact.

Furthermore, it could be identified that employees who can exercise choice over their working patterns as flexworkers (Kanter, 1977). Flexible options are not only powerful in attracting high-caliber people, further, but it also helps to retain them by meeting the needs of a "new and different" pool of talent (Srikantharajaha \& Senathirajab, 2013). Moreover, Georgiana and Constantin (2017) observed that flexible work arrangements are increasing. Most of those are present in top multinational companies and those that demonstrate adaptability to the market's needs and the workers succeed. Similarly, they mentioned that the growing trend of non-standard work arrangements relates to the fast progress of information and communication technologies, and it is transforming the economic and social landscape. Van and Vos (2002) that while flex-work, which is alternatively termed job autonomy, allows workers to more easily manage work activities in relation to non-work activities, it appears that in some cases, it makes it easier for non-work activities to intrude on work.

With the rise of information and telecommunication technologies, 
companies are today able to implement a broad transformation in their work activities by distributing roles and functions widely across different geographical areas, and the processing of their services do not require any more direct physical customer interface (Furaker, Hakansson \& Karlsson 2007; Messenger \& Ghosheh, 2010). Additionally, they stated that as an example, working hours are usually 8.30-5, but when organizations are not worried about the time that the people come for work, but worrying about whether they have achieved the goal or not, motives employees more effectively, especially those who are in software development. However, IT firms adopt various 'poaching' strategies to recruit IT personnel, creating a high labor turnover in the sector, and this not only influences the performance and stability of the sector but also increases the costs of recruitment and selection (Jinadasa \& Wickramasinghe, 2005). Furthermore, they stated that specifically, no studies had been conducted on workplace flexibility strategies in the Sri Lankan context and the preliminary investigations into Sri Lankan firms revealed that the IT sector has begun to experiment with flexitime for managerial and professional employees.

According to Hegewisch and Gornick (2008), most high-income countries have introduced flexible working statutes to make it easier for employees to change how many hours and when and where they work within their current job. Further, they stated that flexible working statutes enhance the ability of individual employees to find solutions that allow work-life reconciliation but in a manner that takes account of employers' business and operational requirements. According to Rice (2017), most flexwork would be impossible without the use of Information and Communication Technologies (ICTs), as they allow communication, collaboration, and the use of resources across time, space, participants, and work-family boundaries. Furthermore, flex-work may benefit one domain while harming another or require a reconceptualization of behaviors and norms in one or more domains. ICTs play a central role in these developments and their implications. According to Srikntharajah and Senathiraja (2013), IT Companies need to thrive every day, which requires new ideas very often than ever before in history, and IT firms not only cater to the needs of local companies but also focusing on international companies primarily through BPO (Business Process Outsourcing). However, among some positive outcomes of implementing flex-work in a workplace, many negatives of flexwork have been identified (Weerasinghe \& Jayawardana, 2019).

During the period of the COVID-19 pandemic, flexible work environments are increasingly spread over space and time and defined by employees due to individual job preferences, organizational policies, and task requirements. A global study entitled "The growing popularity of flexible work arrangements" shows that flexible work arrangements are increasingly being used as a tool for both changing lifestyles and business needs. It revealed that 81 percent of businesses worldwide offer their 
employees a level of flexibility over when and where they work. Globally, 60 percent of businesses believe that flexible work practices are more costeffective than fixed office jobs. However, with the uncertain business world and intense challenges created by rivals, the companies are required to reach certain standards by improving their performance to meet the customers' expectations; otherwise, a lot of problems will surface, including running the risk to liquidate the business.

Moreover, Kipkoech (2018) mentioned that flexible working arrangements are emerging issues in the human resource management field. When it considered the adverse outcomes associated with ICTs in flex-work, disadvantages of using ICTs in flex-work include worker isolation, less organizational visibility, fewer rewards and face-to-face interactions, less observability by management, reduced control of important information, less teamwork, increased safety issues, and greater stress, burnout, and intention to leave (Ayyagari, Grover \& Purvis, 2011; Kaufman \& Scarborough, 2006; Valcour \& Hunter, 2008; Wadsworth, Facer \& Arbon, 2010, for more review see: Rice, 2017). Furthermore, Georgiana and Constantin (2017) found that there have been situations in which such flexibility offered to the employees of a company failed to reach the expected targets, and entirely on the contrary, it bought inefficiency.

Considering all the ideas reported above, this study area is more important to research due to the gaps mentioned above. That is why the present study intends to address that lacuna in the literature. Accordingly, this study has revealed that a relatively fewer number of studies have attempted to explain the impact of flexwork on employee performance. Among such previous research studies that have attempted to examine the impact of flex-work and employee performance in different countries, there is no research evidence regarding the impact of flex-work on employee performance in the Sri Lankan context after this COVID-19 pandemic as well. Similarly, this study addresses the lacuna in empirical studies examining the impact of flex-work on employee performance of executive-level employees in the IT Industry in Sri Lanka. Hence, examining the impact of flex-work on employee performance of executive-level employees in the IT industry in Sri Lanka is the primary purpose of this study.

\section{Research Questions}

i. What is the level of employee performance of executive-level employees in the IT Industry in Sri Lanka?

ii. What is the level of flex-work of executive-level employees in the IT Industry in Sri Lanka?

iii. What is the association between flex-work and employee performance of executive-level employees in the IT Industry in Sri Lanka?

\section{Literature Review}

\section{Employee Performance}

Within the framework of the professionals, good employee performance mirrors the ability to contribute through their works leading to the behavioural achievement that is 
in accordance with the company's goals (Muda, Rafiki \& Harahap, 2014). Accordingly, employee performance means the ability of an employee to perform the job in a particular way that leads both organization and the employee to achieve their common goals and objectives (Mendis \& Weerakkody, 2017). Employee performance includes executing defined duties, meeting deadlines, employee competency, and effectiveness and efficiency in doing work (Iqbal, Anwar \& Haider, 2015). According to Kipkoech (2018), employee performance is defined as a work-related task that is expected on employees and how well the task was done. Meanwhile, the level of the enterprises' success depends on the performance of the human resource management.

Additionally, Dahkoul (2018) mentioned that performance incorporates the resulting outcomes of the performed actions of employees based on their expertise and skills. According to Hawthorne studies and much other research on worker productivity, workers highlighted that employees who are satisfied with their job would have higher job performance, thus supreme job retention, than those who are not happy with their jobs (Landy, 1985). Moreover, it is stated that employees are more likely to turnover if they are not satisfied and hence demotivated to show good performance. Furthermore, in organizational settings, employees' performance is the accumulated result of all the employees' skills, efforts, and abilities to improve organizational productivity leading towards its goal achievement. According to Anitha
(2014), employee performance is basically outcomes achieved, and accomplishments made at work.

Performance can be measured monthly, quarterly, semi-annually, or annually to improve an identified segment in the business (Dessler, 2008). According to research conducted by Georgiana and Constantin (2017), offering flexible jobs also comes with certain risks. However, companies need to adapt to employees' needs and find solutions that can address potential performance issues. Moreover, if employees are satisfied with their jobs and the organization, they are more keenly interested in performing well towards organizational goal achievement (Harter, Schmidt \& Hayes, 2002). According to Anitha (2014), employee performance indicates the financial or non-financial outcome of the employee that has a direct link with the performance of the organization and its success, and a number of studies show that an important way to enhance employee performance is to focus on fostering employee engagement.

Additionally, performance refers to keeping up plans while aiming for the results. Employee performance is higher in happy and satisfied workers, and the management finds it easy to motivate high performers to attain firm targets. (Kinicki \& Kreitner, 2007).

The level of employee performance is highly determined by the level of commitment an employee has toward their organization and its values (Selvarasu \& Sastry, 2014, as cited in Sendawula, Kimuli, Bananuka \& Muganga, 2018). According to Dahkoul (2018), employees' performance depends on their internal 
satisfaction with their job. Organizational performance can be described as the accumulated end result of all the organization's work processes and activities. Improved organizational performance indicates the efforts towards goal achievement while requiring more efforts in terms of improved employee performance (Ellinger, Ellinger \& Keller, 2003). Additionally, employee performance is among the critical factors that contribute significantly to organizational success. Furthermore, Mendis and Weerakkody (2017) stated that performance means the results of a person's activity or an organization.

Based on the psychometric theory, Pradhan and Jena (2017) classified employee performance into three distinct dimensions: task performance, adaptive performance, and contextual performance. According to Koopmans et al. (2013), task performance can be defined as the proficiency with which individuals perform the core substantive or technical tasks central to his or her job. Furthermore, behaviours used to describe task performance often include work quantity and quality, job skills, and job knowledge. In addition to that, Pradhan and Jena (2017) stated that performance in task performance comprises explicit job behaviours that include fundamental job responsibilities assigned as a part of the job description. Moreover, the primary antecedents of task performance are the ability to do the job and prior experience and in an organizational context, task performance is a contractual understanding between a manager and a subordinate to accomplish an assigned task.
Voirin and Roussel (2012) defined adaptive performance as an individual's ability to change their work behaviour to face the changes occurring in the new environment. According to Griffin, Neal, and Parker (2007), adaptive performance can be defined as the extent to which an individual adapts to changes in the work role or environment. Furthermore, an individual's ability to acclimatize and provide the necessary support to the job profile in a dynamic work situation is referred to as adaptive performance (Hesketh \& Neal, 1999). Employees display adaptive performance by changing their behaviour according to the changes in work situations and events (Pulakos, Arad, Donovan, \& Plamondon, 2000).

According to Pradhan and Jena (2017), contextual performance is a kind of prosocial behaviour demonstrated by individuals in a working setup. Accordingly, such behaviors are expected of an employee, but they are not overtly mentioned in one's job description. Therefore, these kinds of unstated expectations are called prosocial behavior or extra-role behavior. Moreover, extra-role behaviors are the contextual performance activities involving proactiveness, discretionary, and deliberate employees' behaviors that are outside the job description, employment contract, or associated with the main job tasks (Banahene, Ahudey \& Asamoah, 2017; Organ, 1997; Schnake, 1991; Organ, 1988; Bateman \& Organ, 1983; Smith, Organ \& Near, 1983, for more review see: Abiante, 2018). 


\section{Flex-work}

Flexible work practices are now available to an increasing number of employees across diverse industries (Richardson \& McKenna, 2014). Citing evidence from Lambert, Marler, and Gueutal (2008), Weerasinghe and Jayawardana (2019) stated that flexwork or flexible work arrangements are defined as the employer-provided benefits that permit employees an extent of control over when and where they have to work. According to Dombrowski et al. (2007), flexibility is present in an organization that allows employees to work beyond the standard protocols and procedures. The term flexible work practices cover diverse work arrangements such as telecommuting, a compressed workweek, working from home a few days a week or at particular times of the year/month, which suggests that flexibility may incorporate variability in location, time, function, quantity and, indeed, the employee him or herself (Swan \& Fox, 2009).

According to Mihhailova (2009), telework, telecommuting, distance work, remote work, flexible work, Flexi-work, flex-work, and e-work are often used as synonyms for some geographical differences. Furthermore, in the USA, the term "telecommuting" is used more commonly, Europeans prefer telework and Japanese flexwork. However, Maxwell, Rankine, Bell, and Macvicar (2007) stated that flex-work is one example of the broader category of 'telecommuting' practices comprising "any policies and practices, formal or informal, which permit people to vary when and where work is carried out." Additionally, it is a situation where, like telecommuting, "workers are given (opportunities) to work from home rather than reporting to a centralized office location" on a daily basis (Richardson, 2009). Goodman and Kaplan (2018) stated that, unlike elite Western families, rural Indian families could not afford to pay for childcare or domestic workers.

Furthermore, they mentioned that the major local employer, a nongovernmental organization that ran various economic development projects, offered family-friendly policies such as day-care or flex-time. Citing evidence from Maxwell et al. (2007) Richardson (2009) indicated that a flexible work arrangement is a formal or informal policy adopted by organizations that allow workers to flex schedule and workplace. Moreover, flexible work differs from the regular working hours being in the office five days per week, from 9.00 am to 5.00 $\mathrm{pm}$, in the sense that it describes the ability to establish a working schedule as per the interest of both the company as well as of the employee (Grantham, 2000; Pettinger, 2002 as cited in Georgiana \& Constantin, 2017). Further, they stated that work patterns could be customized as per the needs of the business, and employees can choose to work from home a few days per week, or they can opt for an alternative work schedule. Moreover, flex-work integrates work with the rest of the life domain and creates a borderless job and a borderless life (Weerasinghe \& Jayawardana, 2019).

Flexible working practices are normally implemented to give employees a degree of choice over how much (operational flexibility), when (time flexibility), and where (location flexibility) they should work, and to 
help them achieve a more satisfying work-life balance; as such, one would not expect the implementation of flexible work to result in the intensification of work (Opatha, 2009; Kelliher \& Anderson, 2010). According to Richardson (2009), flexwork provides opportunities to live 'more fully,' 'holistically' or 'together' and further this notion of living both the home and work self at once, or at least in closer proximity, was closely connected with the belief that in the context of flex-work, like telework, the boundaries between home and work become blurred.

According to Jarrett (1994), flex-work candidates cannot maintain a standard eight-hour shift in a traditional work setting. From the employee's perspective, flexible work may allow more freedom to organize their employment to fit in with other parts of their life (Lucia \& Alzbeta, 2010). Furthermore, flex-work implies the variation in time and place of the job and the sharing of the job, career breaks, part-time and term-time working (Shagvaliyeva \& Yazdanifard, 2014). Moreover, they mentioned that different researchers had discussed various categories of flex-work such as; flexi-time (flexibility in scheduling), tele-homeworking (flexibility in location), and part-time (flexibility in the length of the work) work. Additionally, flex-time work arrangement is part of the many types of flexible working approaches used by organizations globally (Mwebi \& Kadaga, 2015). According to Richardson and McKenna (2014), flexworking is characterized by increased proximity between work and non-work activities, which requires a reconfiguration of space. Further, for some of the flex workers, work had to be reorganized in a space that also required restructuring family relationships. Flexibility to control work location is rarely available for lower-level jobs: however, it benefits middle- and upper-level employees, provided that individuals can control separation from work when desired and self-regulate complexity (Kossek \& Lautsch, 2018).

Moreover, citing evidence from Rau (2003) Rawashdeh, Almasarweh, and Jaber (2016) defined flexible work arrangements as work outside of company hub or the scheduled working hours and workweek hours, and without the spatial borders or physical confines of a traditional office location. Weerasinghe and Jayawardana (2019) mentioned that flex-work had been operationalized by Clark (2001) through two dimensions; temporal flexibility and operational flexibility. Moreover, temporal flexibility indicates the extent of the ability to choose one's work schedule, while operational flexibility is the extent of control over the conditions of one's work.

According to Weerasinghe and Jayawardana (2019), among some positive outcomes of implementing flex-work in a workplace, many negatives of flex-work have been identified. Importantly, the results of their study showed that flex-work leads to role conflicts and also that role conflicts could partially mediate the effect of flex-work on work-life balance. However, flexible work arrangements were successful as they can benefit both employees and employers (Jacobs \& Gerson, 2004; 
Bird, 2006; Kang, 2006; Lewis, Noden \& Sarre, 2008; Cullbreath, 2010; Palmeri, 2013). Moreover, they stated that for the employers it enhances firms' productivity and efficiency, attract well-educated applicant, strengthen the organization recruitment strategy, and reduce the overhead cost while employees benefited from additional time to manage their family demands, increased job satisfaction, lower absenteeism and turnover, and higher productivity. According to Taskin, Donis, and Caesens (2019), the advantages of flex-work are vastly presented in the literature. Hence, to cut a long story short, the significant benefit for organizations to adopt flexwork resides in the financial benefits it may generate through the reduction of space and associated real estate costs (Salomon, Schneider \& Schofer, 1991; Fesltead, Jewson \& Walter, 2005; Baldry \& Barnes, 2012).

Furthermore, they stated that the perspective of the increase in organizational and job performance constitutes another motivation for implementing flex-work. However, citing evidence from Creagh and Brewster (1998), Weerasinghe and Jayawardana (2019) mentioned that in most UK companies, flex-work has not proved to be cost-effective and seems to be actually disliked by managers, and has, therefore, been discontinued. Moreover, there are generally negative outcomes associated with flex-work. Clifton and Shephard (2004) stated that flex-work programs raise costs (insurance, productivity), labor force composition, equity for those without families, reduced salary compensation, uncertainty about actual organizational benefits, and intrusion of the worker's life. Similarly, flex-work options can increase isolation from the office environment and face-to-face interaction, thus lowering the valued job characteristic of task interdependence and a sense of organizational affiliation (Feldman \& Gainey, 1997; Morganson, Major \& Oborn, 2010). Having considered all the ideas reported above, it could be concluded that flex-work has both negative and positive outcomes.

\section{Flex-work and Employee Performance}

According to Vaatstra (2012), the effects of flex-work practices have been extensively researched but are still being discussed. Similarly, there is no conclusive evidence of the impact of flex-work on performance (Menezes \& Kelliher, 2011). Offering flexibility is an effective mechanism that human resource management can help to create an effective association between employees and company goals (Apgar, 1998). Offering flexible jobs also comes with certain risks; however, it is important for companies to adapt to employees' needs and find solutions that can address potential performance issues (Georgiana \& Constantin, 2017). Moreover, flex-work creates a timeless and borderless job, and it is very difficult for a flex-worker to unplug himself/herself from home (Weerasinghe \& Jayawardana, 2019).

Georgiana and Constantin (2017) mentioned that LiveOps, which was established in 2001, with headquarter in Arizona and has quickly developed to the biggest marketplace for call center operations, having more than 20,000 agents worldwide which handle more than 114 million call interactions 
annually and due to the extended work flexibility offered to its employees, it was also awarded the Alfred P. Sloan Award "Business Excellence in Workplace Flexibility." Moreover, organizations that allow operational flexibility will not only have more satisfied and productive employees but that these employees will also have the freedom to manage their family lives in ways that will lead to higher family functioning and satisfaction in family life (Bailyn, 1993). According to Srikantharajaha and Senathirajab (2013), the most obvious payoff of flexibility: employees can concentrate without being interrupted by phone calls, meetings, and other workplace distractions. Further, they mentioned that it has helped the millennium generation to be more productive. Because each person will work accordingly with his nature, some might be productive during the latenight while some might be productive in the early morning or during the daytime.

Similarly, this will help them to increase their job performance. Moreover, Eaton (2003) mentioned that flex-work is associated with increased (self-perceived) performance and decreased turnover via increased affective commitment (loyalty and willingness to contribute) or citizenship behavior. Furthermore, organizations can benefit from a higher perceived organizational performance when they offer flex-work practices (Perry, Smith \& Blum, 2000).

According to Kipkoech (2018), Flexible working generally makes workers productive, hence, high performance to the employee. Furthermore, employees who are placed on the flexible program will be happier at work and less prone to burnout and stress than employees on fixed-job, hence productivity is realized. In many cases, employers report that flexible scheduling increases productivity (Solomon, 1996). Flex-work can provide many benefits, including improved health and work-family balance, worker engagement, commitment, attachment, and lower absenteeism (Mcnamara, Pitt-catsouphes, Brown \& Matz-costa, 2012; Gajendran \& Harrison, 2007; Karunarathne, Froese, \& Barder, 2019; Kossek, Pichler, Bodner \& Hammer, 2011). Flexible work arrangements may help employees enhance their job performance (Gajendran \& Harrison, 2007; Lee, MacDermid, Williams, Buck \& LeibaO'Sullivan, 2002). As indicated by the above evidence from literature, flex-work has successfully enhanced employee performance in some instances. It could be explained that there are some positive consequences of flex-work on employee performance.

In opposition with the above empirical evidence regarding the positive impact of flex-work on employee performance, Georgiana and Constantin (2017) stated that there had been situations in which such flexibility offered to the employees of a company failed to reach the expected targets, and quite on the contrary, it bought inefficiency. Kossek and Lautsch (2018) stated that if some occupations are not deriving positive outcomes because of lack of access to the type of flexibility they need or experiencing stigma or negative consequences from using flexibility policies, this is important for managing 
societal workforce stress, productivity, and the ability of diverse employee occupational groups who need the flexibility to benefit from these policies and practices. Further, implementing flexible working arrangements in a working setup, employees' perceptions about the consequences of using such policies must be considered (Guest, 2001). When considering the negative outcomes associated with ICTs in flexwork, disadvantages of using ICTs in flex-work include worker isolation, less organizational visibility, fewer rewards and face-to-face interactions, less observability by management, reduced control of important information, less teamwork, increased safety issues, and greater stress, burnout, and intention to leave (Ayyagari, Grover \& Purvis, 2011; Kaufman-Scarborough, 2006; Valcour \& Hunter, 2008; Wadsworth, Facer \& Arbon, 2010, for more review see; Rice, 2017). Moreover, Bloom et al. (2013) stated that ICT use could foster a more significant workload, multitasking, poorer work environment, and stress. Having considered all the ideas reported in this paragraph, it could be concluded that there are some instances in which the flex-work has not achieved the anticipated organizational goals and objectives. Hence, it could be stated that there are some negative consequences of flex-work on employee performance as well.

According to Georgiana and Constantin (2017), the company offering such flexible work benefits should track the organizational performance of homeworking implementation and, if there are any loopholes, should look to mitigate them. Further, they stated that to demonstrate the importance of work flexibility and its influence on overall organizational performance, they also made a parallel between the business strategy of each company and the type of labor flexibility offered to obtain profit and growth of the business. While some studies show an increase in performance, others demonstrate the negative consequences such as increasing levels of absenteeism, problems of concentration, or excessive stress for individual and organizational performance (Green, 1993; Sundstrom, Town, Rice, Osborn, \& Brill 1994; Smith, Jackson \& Klein, 2009 as cited in Taskin, Donis \& Caesens, 2019). According to Rice (2017), flex-work may foster positive and negative outcomes related to performance, hiring and retention, stress, and work-life balance. Hence, it could be concluded that there is a significant impact of flex-work on employee performance.

\section{Model and Hypothesis}

Based on the prior literature, the researchers identified a significant impact of flex-work on employee performance. Therefore, the conceptual model depicted in Figure 1 as follows. Similarly, flex-work is considered the independent variable, whereas employee performance is considered the dependent variable. 


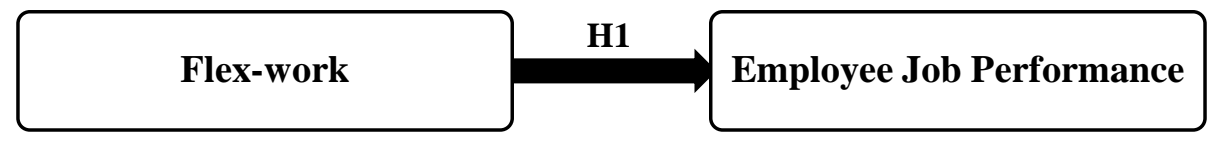

\section{Figure 1: Conceptual Framework}

Source: Authors, 2021

According to Weerasinghe and Jayawardana (2019), among some positive outcomes of implementing flex-work in a workplace, many negatives of flex-work have been identified. Importantly, the results of their study showed that flex-work leads to role conflicts and also that role conflicts could partially mediate the effect of flex-work on work-life balance. However, flexible work arrangements were successful as they can benefit both employees and employers (Jacobs \& Gerson, 2004; Bird, 2006; Kang, 2006; Lewis, Noden \& Sarre, 2008; Cullbreath, 2010; Palmeri, 2013). Additionally, Rice (2017) found that flex-work may foster positive and negative outcomes related to performance, hiring and retention, stress, and work-life balance. Hence, it could be concluded that there is a significant impact of flex-work on employee performance.

Therefore, based on existing literature, the researchers suggest that there is a significant impact of flex-work on employee performance. Accordingly, below mentioned hypothesis is advanced in the current study to be tested with primary data. This hypothesis will depend on the influence of the reaction of the independent variables of the study, and it can be developed as follows. Therefore, based on existing literature, the researchers developed the following hypothesis.
H1: There is a significant impact of flex-work on employee performance

\section{Methodology}

\section{Sample and data collection procedure}

To test the hypothesis, data were collected from executive-level employees who are working for three leading IT firms in Western Province, Sri Lanka. The population was 300 executive-level employees, and according to Krejcie and Morgan (1970), the required sample for analysis was 169 . Following the simple random sampling method, researchers selected 169 participants and distributed the survey among them. However, researchers received only 153 surveys back for data analysis. Therefore, the response rate was $90.53 \%$.

\section{Measures}

\section{Independent Variable - Flex- work}

To measure flex-work, we used the 10item scale developed by Clark (2001). The example items are 'I am able to arrive and depart from work when I want, I am free to work the hours that are best for my schedule' (temporal flexibility) and 'I have a say in what goes on at work, I can choose what I do at work.' (operational flexibility). The answer options range from strongly 
agreed (05) to strongly disagree (01). The Cronbach alpha was 0.911 .

\section{Dependent Variable - Employee Job Performance}

We assessed employee performance using the 12-item scale developed by Pradhan and Jena (2017). The answers were range from strongly agreed (05) to strongly disagree (01), and the example items include 'I use to maintain a high standard of work, I am capable of handling my assignments without much supervision (task performance), 'I use to perform well to mobilize collective intelligence for effective teamwork, I could manage change in my job very well whenever the situation demands' (adaptive performance), 'I used to extend help to my co-workers when asked or needed, I love to handle extra responsibilities' (contextual performance). The Cronbach alpha was 0.935 .

In addition, we assessed the participants' demographic information, which finds important for understanding the nature of the participants. Accordingly, the majority of survey participants are male, and the majority are married. Most of the respondents have more than three years of working experience. Moreover, the majority of the respondents in the sample are in the 31-35 age level.

\section{Preliminary Data Analysis}

Before testing the hypothesis, researchers tested the validity and reliability of the instrument that we used to collect the data. First, we tested the reliability using Cronbach's Alpha test method. Moreover, we tested the validity of the instrument using KMO and Bartlett's test. The results show that instrument is highly reliable since the Cronbach's Alpha values are more than 0.7 . KMO value is more significant than 0.7 , and therefore, it shows that factor analysis was appropriate for this data.

Additionally, Bartlett's test is significant for these data, as the level of significance result is 0.000 , which falls below 0.05. Accordingly, factor analysis will be more useful when Sig. Value is less than 0.05 at $95 \%$ confidence level. In addition, researchers tested descriptive statistics, i.e., mean, standard deviation, and inter-item correlation coefficients, which illustrate in Table 1. 
Table 1: Result of Correlation Analysis, Mean, Standard Deviation

\begin{tabular}{|c|c|c|c|c|c|c|c|c|c|}
\hline No. & Variable & $\mathrm{M}$ & SD & 1 & 2 & 3 & 4 & 5 & 6 \\
\hline 1 & Flex-work & 3.89 & .62 & & & & & & \\
\hline 2 & $\begin{array}{l}\text { Employee } \\
\text { Performance }\end{array}$ & 4.27 & .37 & $.521^{* *}$ & & & & & \\
\hline 3 & Gender & 1.66 & .47 & $.397^{* *}$ & $.294^{* *}$ & & & & \\
\hline 4 & Civil Status & 1.59 & .49 & $.238^{* *}$ & .040 & $.241^{* *}$ & & & \\
\hline 5 & Age & 2.67 & 1.04 & $.513^{* *}$ & $.323^{* *}$ & $.446^{* *}$ & $.650^{* *}$ & & \\
\hline 6 & $\begin{array}{l}\text { Working } \\
\text { Experience }\end{array}$ & 3.54 & .92 & $.235^{* *}$ & .151 & $.357^{* *}$ & $.501^{* * *}$ & $.581^{* *}$ & \\
\hline
\end{tabular}

**. Correlation is significant at the 0.01 level (2-tailed).

Note: $\mathrm{N}=153 ; \mathrm{M}=$ Mean; $\mathrm{SD}=$ Standard Deviation

Source: Survey Data, 2021

\section{Testing Hypothesis}

To test the hypothesis, we ran simple linear regression. In hypothesis 1 , we proposed that there is a significant impact of flex-work on employee performance. As we proposed, the result shows that flex-work significantly influence on employee performance $(\beta=0.52, \mathrm{p}=0.000, \mathrm{t}=7.50)$. Thus, hypothesis 1 is accepted. Moreover, the regression results report a significance variance of the model $(\mathrm{R} 2=0.272, \mathrm{p}=$ $0.000, \mathrm{~F}=56.320)$.

Kelaniya Journal of Human Resource Management

\section{Discussion, Theoretical, and Practical Implications}

The results show that there is a significant impact of flex-work on employee performance. It revealed that flex-work has a $27.2 \%$ impact on employee performance of executive-level employees in the IT Industry in Sri Lanka. Further, it means that $72.8 \%$ of unexplained factors impact employee performance of executive-level employees in the IT Industry in Sri Lanka. The findings are consistent with prior studies that found flex-work significantly influences employee performance. According to Rice (2017), flex-work can positively and negatively affect performance, hiring and 
retention, stress, and work-life balance. However, as explained in the literature review, the findings related to flexwork and performance are inconsistent. Thus, the study's findings help better understand the impact of flex-work on employee performance and fill the gap in the literature.

The findings provide some insights to practitioners as results suggest flexwork help to improve employee performance. Therefore, we recommend that policymakers and the government adapt to the prevailing pandemic situation by developing proper mechanisms to enhance employee performance by improving flex-work. Moreover, the new Human Resources paradigm should concentrate on developing policies to reduce the anxiety of employees, stakeholders with positive communication and allocating some resources to maintain the disturbances of the COVID-19 situation. Furthermore, Human Resource approaches and strategies must fit the overall business strategy to achieve organizational goals and gain the desired business sustainability. Accordingly, organizations can implement flex-work as a strategy, especially these days.

Moreover, these study findings will further help the researchers in future career development as Human Resource Management professionals develop certain guiding principles that will assist in developing strategies to enhance employee performance among the particular employees. Hence, the findings of this research provide several practical implications to managers in IT Industry and the managers in other industries, and the decision-makers such as directors and the HR department for understanding how executive-level employees' performance is improved. Moreover, most of the organizations in the world will confront backlogs and increased workloads following the COVID-19 crisis. Additionally, the COVID-19 pandemic has resulted in a massive, unexpected, and sudden disruption to billions of businesses in many sectors of the world. However, the organizations can benefit from the recruitment and selection process while recruiting and selecting managers capable of adapting flex-work practices. Moreover, the managers can gain benefits from the training and development programs to improve the flex-work practices to increase employee performance. Therefore, the managers of the industry should consider flex-work when recruiting, selecting, and training employees.

The findings of this study are helpful for every business organization because effective flex-work is a contemporary strategy for every organization to reach organizational success while enhancing employee performance. Accordingly, flex-work helps employees to enhance their employee performance. Therefore, if organizations can implement flex-work practices, the organizations can enhance employee performance. Furthermore, this study contributed to the academias and researchers by providing valuable information to those seeking to explore and investigate the impact of flex-work on employee performance. Moreover, the findings of the study are helpful to future researchers as well. 


\section{Limitations and Avenues for Future Researchers}

This research strengthens the existing knowledge of flex-work literature, employee performance literature, and human resource management literature. Moreover, this study fulfills the gap related to flex-work on employee performance, especially in the IT Industry in Sri Lanka. However, there are several limitations to this study.

One of the limitations of this study is that the scope of the study selected for the research is narrow. Hence, it could be suggested that future researchers should attempt to extend the scope of the study by including more companies in the IT industry in order to generalize the findings of the research. Furthermore, the research is limited to executive-level employees. Therefore, future researchers could extend the population of the study by including the different levels of employees in addition to the executive-level employees. Therefore, future researchers need to be tested this impact with the different categories of employees, such as the operational level employees.

Additionally, since this study followed the quantitative approach, future researchers can follow a mixed approach to improve the quality of the study. Similarly, as this study is a cross-sectional study, future researchers need to collect data at different times to reduce common method bias. Moreover, the research measured employee performance through self-evaluation from the employees. Hence, sometimes it might not obtain accurate information about the actual performance of the employees. However, it is not enough to consider self-evaluation only when measuring employee performance and need to get feedback from the direct reporters, managers, peers, and customers. Therefore, future researchers need to measure employee performance by using the 360-degree method. They could then be gained the evaluation of the employee performance by direct reporters, managers, peers, and customers. Furthermore, the researchers have not included any moderator or mediator in the research model. Thus, future researchers toned to test the mediation effects such as job satisfaction, organizational culture, work-life balance, and the moderating effect of employees' attitudes towards flex-work and psychological well-being.

\section{Conclusion}

The objective of this study was to examine the impact of flex-work on employee performance. To achieve this objective, we collected data from 153 executive-level employees from three IT industry organizations in Western Province, Sri Lanka. The results of regression analysis showed that there is a significant impact of flex-work on employee performance. Additionally, it revealed that flex-work has a $27.2 \%$ impact on employee performance of executive-level employees in the IT Industry in Sri Lanka. It means that $72.8 \%$ of unexplained factors impact employee performance of executivelevel employees in the IT Industry in Sri Lanka. 


\section{References}

Abiante, I. D. (2018). Organizational citizenship behaviour and employee performance in Nigeria deposit money banks, Rivers State. International Journal of Advanced Academic Research, 4(12).

Anitha, J. (2014). Determinants of employee engagement and their impact on employee performance. International Journal of Productivity and Performance Management, 63(3), 308-323.

Bourdeau, S., Malaterre, A. O., \& Houlfort, N. (2019). Not all work-life policies are created equal: career consequences of using enabling versus enclosing worklife policies. Academy of Management Review, 44(1), 172-190.

Clark, S. C. (2001). Work Cultures and Work/Family Balance. Journal of Vocational Behavior, 58, 348-365.

Dahkoul, Z. M. (2018). The determinants of employee performance in Jordanian organizations. Journal of Economics, Finance and Accounting, 5(1), 11-17.

Dombrowski, C., Kim, J. Y., Desouza, K. C., Braganza, A., Papagari, S., Baloh, P., \& Jha, S. (2007). Elements of innovative cultures. Knowledge and Process Management, 14(3), 190-202.

Elnaga, A., \& Imran, A. (2013). The effect of training on employee performance. European Journal of Business and Management. 5(4).

Georgiana, C., \& Constantin, A. (2017). Empirical study regarding flexible work proliferation in multinational companies. Proceedings of the 11th International Management Conference.

Goodman, R., \& Kaplan, S. (2018). Work-life balance as a household negotiation: a new perspective from rural india. Academy of Management Discoveries. 5(4).

Hegewisch, A., \& Gornick, J. C. (2008). Statutory routes to workplace flexibility in cross-national perspective.

Iqbal, N., Anwar, S., \& Haider, N. (2015). Effect of leadership style on employee performance. Arabian Journal of Business and Management Review, 5(5).

Jarrett , J. E. (1994). Exploratory analysis of telecommuting projects involving persons with disabilities.

Karunarathne, R. A. I. C., Froese, F. J., \& Bader, A. K. (2019). Relocation with or without you: An attachment theory perspective on expatriate withdrawal. Proceedings of the Academy of Management Annual Meeting, 2019, 14831. doi:10.5465/AMBPP.2019.12 
Kipkoech, K. V. (2018). Flexible working arrangements on employee performance in kericho county referral hospital, Kenya, Dissertation.

Kossek, E. E., \& Lautsch, B. A. (2018). Work-life flexibility for whom? Occupational status and work-life inequality in upper, middle and lower level jobs. Academy of Management Annals, 12(1), 5-36.

Krejcie, R. V., \& Morgan, D. W. (1970). Determining sample size for research activities. Educational and Psychological Measurement, 30, 607-610.

Lucia, T., \& Alzbeta , K. (2010). Working time arrangement options in the slovak republic. Journal of Competitiveness, 129-140.

Maxwell, G., Rankine, L., Bell, S., \& MacVicar, A. (2007). The incidence and impact of flexible working arrangements in smaller businesses. Employee Relations, 29(2), $138-161$.

Mendis, M., \& Weerakkody, W. (2017). The Impact of work life balance on employee performance with reference to telecommunication industry in Sri Lanka: A mediation model. Kelaniya Journal of Human Resource Management, 12(1), 72-100.

Mihhailova, G. (2009). Management challenges arising from the use of virtual work. Baltic Journal of Management, 4(1), 80-93.

Muda, I., Rafiki, A., \& Harahap, M. R. (2014). Factors influencing employees' performance: A study on the islamic banks in Indonesia. International Journal of Business and Social Science, 5 (2), 73-80.

Mwebi, M. B., \& Kadaga, M. N. (2015). Effects of flextime work arrangement on employee performance in nairobi CBD commercial banks. International Journal of Novel Research in Marketing Management and Economics, 2(3), 111-121.

Opatha, P. H. (2003). Introduction to Human Resource Management. Sri Lanka: Author.

Pradhan, R. K., \& Jena, L. K. (2017). Employee Performance at Workplace: Conceptual Model and Empirical Validation. Business Perspectives and Research, 5(1), 1-17. doi:10.1177/2278533716671630

Pulakos, E. D., Arad, S., Donovan, M. A., \& Plamondon, K. E. (2000). Adaptability in the workplace: Development of a taxonomy of adaptive performance. Journal of Applied Psychology, 85(4), 612-624. doi:10.1037//00219010.85.4.612 
Rawashdeh, A. M., Almasarweh, M. S., \& Jaber, J. (2016). Do flexible work arrangements affect job satisfaction and work-life balance in Jordanian private airlines? International Journal of Information, Business and Management, 8(3).

Rice, R. E. (2017). Flexwork, work-family boundaries, and information and communication technologies. In The Wiley Blackwell Handbook of the Psychology of the Internet at Work (pp. 176-193).

Richardson, J. (2009). Flexwork in Canada: Coping with dis-ease? CMS Conference.

Richardson, J. (2009). The manager and the flexworker: An interpretive interactionist perspective. Management Revue, 20(1).

Richardson, J., \& McKenna, S. (2014). Reordering spatial and social relations: A case study of professional and managerial flexworkers. British Journal of Management, 25, 724-736.

Sendawula, K., Kimuli, S. N., Bananuka, J., \& Muganga, G. N. (2018). Training, employee engagement and employee performance: Evidence from Uganda's health sector. Cogent Business \& Management, 5(1).

Srikantharajaha, M., \& Senathirajab, R. (2013). The impact of innovative-supportive culture on employee performance in software development companies of Sri Lanka. Colombo Business Journal, 4(1).

Taskin, L., Donis, C., \& Caesens, G. (2019). Considering the combination of office designs and telework practices in the study of flexwork effects on well-being and performance.

Vaatstra, G. (2012). Antecedents and effects of use of flexwork practices in times of crisis.

Voirin, A. C., \& Roussel, P. (2012). Adaptive performance: A new scale to measure individual performance in organizations. Canadian Journal of Administrative Sciences, 29(3), 280-293. doi:10.1002/Cjas.232

Weerasinghe, T. D., \& Jayawardana, A. K. (2019). Flex-work and work-life balance: Effects of role conflicts and work-life support organizational culture. Sri Lankan Journal of Management, 24(2), 49-76.

Wickramasinghe, V., \& Jayabandu, S. (2007). Towards workplace flexibility: Flexitime arrangements in Sri Lanka. Employee Relations, 29(6), 554-575. 